\title{
Heroism and Risk of Harm
}

\author{
Douglas M. Stenstrom ${ }^{1}$, Mathew Curtis $^{2}$ \\ ${ }^{1}$ Department of Psychology, California State University Los Angeles, Los Angeles, USA \\ ${ }^{2}$ Annenberg School for Communication and Journalism, University of Southern California, Los Angeles, USA \\ Email: dstenst@calstatela.edu
}

Received October $1^{\text {st }}, 2012$; revised October 29 $9^{\text {th }}, 2012$; accepted November $29^{\text {th }}, 2012$

\begin{abstract}
Although the positive traits and qualities that compose heroism such as courage, bravery and empathy have received research support, little experimental research has directly investigated the perception of heroic acts. The primary purpose of the current research was to address this gap in the literature by investigating a basic question about a central defining feature of heroism, namely the risk of potential harm. A related objective was investigating how implicit theories of personality and moral character influence perceptions of heroism, particularly as it relates to risk of harm. Results revealed how incrementally escalating the level of risk to the actor can transform an otherwise prosocial behavior into heroism through separating altruism from heroism. Implicit theories impacted perceptions of heroism consistent with the theorizing behind entity/incremental orientations, and produced an interactive effect with the situational manipulation through information about the particular level of risk differentially affecting entity and incremental belief systems.
\end{abstract}

Keywords: Heroism; Risk; Implicit Theories; Positive Traits; Moral Character

\section{Introduction}

Given the origins of the word hero (from Greek meaning hero, warrior, protector, defender) (Hero Etymology, 2012) it is not surprising that a heroic act is typically associated with some degree of danger or a martial act in performing the prosocial behavior to help others in need. However, in modern use a hero has evolved beyond physical and dangerous acts to include a wider variety of positive action (e.g. social sacrifice, a whistle blower, or a religious figure) (Franco, Blau, \& Zimbardo, 2011). This is reflected in the traits and virtues associated with heroes that can range from courage and empathy (Staats, Hupp, \& Hagley, 2008) and bravery (Gaster, 1987) to honesty and hopefulness (Staats, Wallace, Anderson, Greesley, Hupp, \& Weiss, 2009). Beyond the connection of heroism to these same positive character traits that are focal to research in Positive Psychology, the concept of a hero is so central to modern society that there has been suggestion that we possess a basic hero archetypal theme or schema (Maloney, 1999), and this is supported by research showing children as young as 5 or 6 years old have developed basic hero classifications and exemplars (White \& O'Brien, 1999).

This centrality of the hero to human culture is reflected in the long history of the hero archetype within human society. Indeed, the hero has been part of human culture for millennia, appearing in ancient cave paintings (Getty Images, 2012) to Greek legends like Hercules or Achilles, and to modern day heroes exemplified by the Carnegie Hero Medal winners announced each year (Becker \& Eagly, 2004). Despite the enduring human propensity and fascination with heroic character traits and exemplars, there is little heroism-focused research. In fact, recent reviews about research related to heroism have asserted that little published research directly investigates heroism (Franco, Blau, \& Zimbardo, 2011) and instead focuses on the broader Positive Psychology-related concepts that compose heroic ten- dencies, such as character strengths/virtues like courage and bravery, prosocial-related research like bystander intervention and empathy, and morality-related research like moral exemplars and affordances (Jayawickreme \& DiStefano, 2012). The purpose of the present research is to address this gap in the literature by investigating a basic question about a central defining feature of heroism, namely the risk of potential harm.

The literature on heroism is so new, in fact, that there is yet no clear definition in the literature, with some researchers quoting dictionaries for their definition (Becker \& Eagly, 2004) and others providing detailed but conflicting versions, such as a multifaceted definition by Franco, Blau, and Zimbardo (2011) that heroism involves five criteria: social activity in service to others, engaged in voluntarily, with recognition of possible risks/costs, with the actor accepting the sacrifice, and no external gain anticipated by the actor. Jayawickreme \& Stefano (2012), on the other hand, provide a separate multifaceted definition with three criteria: atypical situation for the behavior, unusual behavior in part because of personal risk, and furthering welfare of others. The lack of research establishing the essential nature of these criteria further encumbers the progression of research on heroism, particularly because the various definitions involve conflicting criteria.

One commonality among the various definitions, however, appears to be the concept of risk to the hero, even if that risk involves serious physical consequences or loss of life. For example, the elements of heroism proposed by Franco, Blau, and Zimbardo (2011) in the preceding paragraph rest upon the concept of risk (e.g., voluntariness of the risk, recognition of the risk, accepting the risk, etc.). One line of reasoning is that heroism is part of the larger construct of prosocial behavior and that the element of risk is what separates altruism into heroism (see Becker \& Eagly, 2004). One way to investigate this assertion is to empirically manipulate the level of risk. The primary purpose of the current research is to experimentally investigate the per- 
ception of heroism by manipulating the potential risk of harm in order to understand how prosocial behavior can be transformed into heroism through increasing risk to the actor.

In addition to investigating this pivotal situational constraint on heroic action (risk of harm), the related purpose of the present research is to investigate a relevant personality trait that may impact perceptions of heroism, particularly as it relates to chances of potential harm. Implicit theories of human nature are basic meaning systems used by people to understand, interpret, and predict their social world (Hong, Levy, \& Chiu, 2001; Levy, Plaks, \& Dweck, 1999). One key underlying lay belief that shapes cognitions and behavior is the determination people make about the fixedness or malleability of human attributes (Dweck, Chiu, \& Hong, 1995; Dweck \& Leggett, 1988; Levy, Plaks, Hong, Chiu, \& Dweck, 2001). For example, Dweck and colleagues have consistently shown that an entity orientation (believing an attribute such as moral character is fixed) influences perceptions, cognitions and behavior differently than an incremental orientation (believing the attribute is malleable). They further argue that knowing whether something is fixed or malleable is an essential component of human cognition that children must develop before they can understand the physical and social world. This distinction then serves as one of the most fundamental and underlying characteristics that people implicitly hold regarding the objects, processes and attributes in their world.

Within this body of research, studies has consistently shown that the same events can be perceived and interpreted differently based on holding either an entity versus incremental perspective because each is associated with a different informational processing approach (for a review see Dweck, Chiu, \& Hong, 1995; Levy, Plaks, \& Dweck, 1999). By believing human nature is fixed, entity theorists make stable character inferences from a single instance of a person's behavior, even when that behavioral information is ambiguous (Levy et al., 2001; Levy \& Dweck, 1998). Conversely, by believing that human nature is malleable, incremental theorists use factors other than dispositional traits to understand human behavior, such as external situational forces or psychological processes within individuals (e.g., goals, needs, current mood state, etc.). Within the context of the present research, the implication is that incremental theorists will be influenced by situational features of a heroic act, such as increasing levels of risk in the particular heroic situation, whereas entity theorists will perceive heroic behavior consistent with dispositional traits unrelated to situational forces. Prior research has investigated these different processing styles in various domains such as legal and moral character (e.g., Chiu, Dweck, Tong, \& Fu, 1997; Gervey, Chiu, Hong, \& Dweck, 1999), intelligence (e.g., Hong, Chiu, Dweck, Lin, \& Wan, 1999; Dweck \& Leggett, 1988) and social behavior (e.g., Chiu, Hong, \& Dweck, 1997; Erdley \& Dweck, 1993). The current research will investigate the relationship between implicit theories and risk of harm in heroism.

Consistent with the literature on "Person $\times$ Situation" interactions which emphasizes that human nature is best conceptualized as the result of an interaction between aspects of the person and aspects of the situation (see Funder, 2001; Mischel, 2004; Shoda, 2004), investigating both person-variables and situation-variables in the same study will allow a better understanding of the relationship between the two forces upon the perceptions of heroism. Participants will be randomly assigned to evaluate a heroic act with incrementally increasing levels of risk of harm. Based upon a modified version of the measures used by Franco, Blau, and Zimbardo (2011), participants will then evaluate the distinction between altruism and heroism in the prosocial acts. By experimentally manipulating the level of potential risk, the goal is to identify if a threshold-based approach characterizes perceptions of heroism. By also investigating implicit theories as a person-variable, the goal is to identify the interactive effect of both situational and personality factors in evaluating heroic acts.

\section{Methods}

\section{Participants and Design}

The participants were 569 respondents collected online (43.5\% females and $56.5 \%$ males with a mean age of 29.69 years and a standard deviation of 11.0 years) and recruited via Amazon Mechanical Turk which is an online marketplace that provides monetary reward for completing internet-based tasks. Research into the Amazon Mechanical Turk platform has empirical tested its demographically diverse population and reliability in data outcomes in comparison to traditional methods (Buhrmester, Kwang, \& Gosling 2011). All participants were randomly assigned to one of the between-subjects experimental conditions that manipulated the level of risk of harm.

\section{Materials and Procedures}

After providing the instructions for the study, all participants were first randomly assigned to experimental condition before answering the four sets of measures. The manipulation of risk of harm was a depiction of a stereotypical heroic act followed by information about the risk of harm involved in the event. Following a modified form of the methodology from Franco, Blau, and Zimbardo (2011) that used brief hypothetical scenarios to assess perceptions of heroism, we developed a generic description of a heroic act, namely, "A bystander helps retrieve a toddler crawling in the road". Our goal in creating a generic and stereotypical act was to avoid potential confounds from involving situational features not relevant to the risk of harm. For example, additional superfluous information about the number of cars on the road or characteristics of the bystander would inadvertently add new situational features that might change the respondents' perception of the risk of harm. After reading the description, participants were then informed about the risk of harm, namely "In this particular situation, there was a $[0 \%]$ chance of harm to the bystander". The risk of harm ranged between $0 \%$ and $100 \%$ in $10 \%$ increments.

Participants then responded to four types of measures. The main categorical measure of the participants' perception of the scenario was the first type of measure. The question was a forced-choice measure concerning altruism and heroism that asked, "Do you think the actions in the scenario are altruistic, heroic, or neither?". Similar to the work by Franco, Blau, and Zimbardo (2011) we also include the option of "neither" so that the respondents choice more clearly reflects their true intent to gauge the act as a heroic act or an altruistic act. The next type of measure was a continuous measurement of the perceived level of heroism and altruism. Participants were randomly presented two questions on a 100-point sliding scale from "not at all" to "very much" about "To what degree do you think the actions were heroic?", and "To what degree do you think the actions were altruistic?". The sliding scales were represented 
with vertical lines every 10 increments from 0 to 100 to provide a visual gauge as to where they were sliding the scale. The online survey software also showed the exact number of their choice ranging from 0 to 100 on the right side of the sliding scale so that respondents were aware of their exact choice.

The measures of implicit theories were the next set of measures, and involved both implicit theories of personality and implicit theories of moral character as developed by Dweck and colleagues (for a review see Dweck, Chiu, \& Hong, 1995). Participants' implicit theory of personality was measured using the three-item measure used in past research on implicit theories (e.g., Levy, Stroessner, \& Dweck, 1988; Tong \& Chiu, 2002) The items are, "Everyone is a certain kind of person, and there is not much that can be done to really change that", "The kind of person someone is, is something very basic about them, and it can't be changed very much", and "People can do things differently, but the important parts of who they are can't really be changed". The three items for the implicit theory of moral character were also taken from past research (e.g., Chiu, Hong, \& Dweck, 1997; Chiu, Dweck, Tong, \& Fu, 1997; Gervey, Chiu, Hong, \& Dweck, 1999): “A person's moral character is something very basic about them, and it can't be change that much", "There is not that much that can be done to change a person's moral traits (e.g., conscientiousness, uprightness, and honesty)", and "Whether a person is responsible or sincere or not is deeply ingrained in their personality. It cannot be changed very much". Psychometric testing has confirmed that the reliability of each measure and that agreement on the items is not a result of social desirability, self-monitoring, cognitive abilities or demographics like sex and age. Participants indicate their agreement with each item on a 6-point scale ranging from "strongly disagree" to "strongly agree". Responses to each set of questions form a measure of implicit theory (personality, or moral character) with a higher score indicating a stronger belief in entity theory. All the implicit theory items were randomized, and both measures formed high reliability in the present research $(\alpha=.89$ for implicit theory of personality, and $\alpha=.91$ for implicit theory of morality).

Following the measure of implicit theories, the participants responded to the manipulation check question of "In the scenario you read, what was the risk of harm?", with option choices matching the eleven experimental conditions. Participants then answered demographic questions about gender and age before being thanked for their participation in the study.

\section{Results}

Of the 569 total participants, 47 were removed for incorrectly answering the manipulation check question. An additional 32 were removed for not correctly answering an attention check question. Imbedded in the set of implicit theory items was an additional "attention check" question routinely used by the authors that asks respondents "Please click 'strongly disagree' on the scale range". The purpose of the question is to identify if participants are paying attention to the text of the measures in the online study. After removing participants for manipulation check and attention check questions, the resulting data set included 490 participants.

\section{Heroism and Risk of Harm}

The primary purpose of the study was to investigate the role of increasing risk of harm in perceptions of prosocial acts. A chi-square test of the between-subjects experimental manipulations and the main categorical measure of perceptions revealed a significant omnibus effect $\left(\chi^{2}(20, N=490)=59.67, p<.001\right)$. As can be seen from Figure 1, the bystander's prosocial act from the scenario was increasingly perceived as heroism as the potential risk incrementally intensified. After a certain degree of risk the act is no longer seen as altruistic. The fact that the risk of harm is on the low end of the manipulated range before the conversion to heroism occurs appears to indicate that even a low possibility of jeopardy can confer the status of "hero".

An important aspect of the data is that the initial conditions have a very narrow percentage difference between reported altruism and heroism, and are non-significantly different from each other. Although visually there appears to be a specific threshold moment where the prosocial act is transformed between predominantly altruistic to predominantly heroic; instead it should be conceptualized as a non-significant transition between the initial manipulations. In other words, instead of the visual depiction of a transitioning threshold moment between altruism and heroism, there appears to be instead a baseline of uncertainty or ambiguity (e.g., act could be either altruistic or heroic) in the initial levels of risk that then transforms into a definite heroic act as risk increases. Even in the absence of risk $(0 \%)$, respondents are split on whether the act is altruistic or heroic. An interesting aspect of the $0 \%$ condition, for example, is that a sizeable number of respondents indicated that it was "neither" $(18.8 \%)$, as if in the presence of zero chance of harm the act is benign enough to not even constitute altruism for 1 in 5 respondents. In fact, the most interesting aspect of the data is the uncertainty about the act itself in the absence of risk levels, and how it then transformed into a definite heroic act through manipulating rising risk.

As seen in Figure 1, there is a fairly steady incline of heroic perceptions. As risk increases, so do perceptions of heroism. As an additional means of statistical support for this relationship, analyzing the secondary measures of heroism and altruism (the continuous measurements on a 100-point scale) revealed that the risk of harm is associated with only perceptions of heroism, not altruism. A One-Way ANOVA using the eleven experimental conditions as the between-subjects grouping variable found a significant effect for the heroic variable $(F(10,476)=$ $7.68, p<.001)$ but not for the altruistic variable $(F(10,469)$ $=.74, p=.69)$. Figure 2 shows that the perception of heroism increases as the situational features of the scenario increases (risk of harm), thus providing additional support for the chi-square analysis in the previous analysis. Treating heroic perceptions as continuous (rather than as forced-choice) reveals an even more refined understanding of the nature of the relationship. When there is no risk of harm $(0 \%)$, the perception of the prosocial acts as heroic are still somewhat high (52.04 on the 100-point scale) even at this baseline level of zero danger to the bystander. Second, there appears to be stages of increasing perceptions of heroism with plateaus or clusters at $10 \% / 20 \%$, $30 \% / 40 \% / 50 \%$, and $80 \% / 90 \% / 100 \%$. That said, the gradual incline of responses renders non-significant differences between each pairwise change in risk levels so the data would be better conceptualized as linear. A test of linearity, in fact, found the relationship between risk and heroism to be linear (the linear term is significant but the deviation from linearity is non-significant, $p s<.001$, and .90 , respectively). A correlation treating the manipulation as continuous with the continuous 


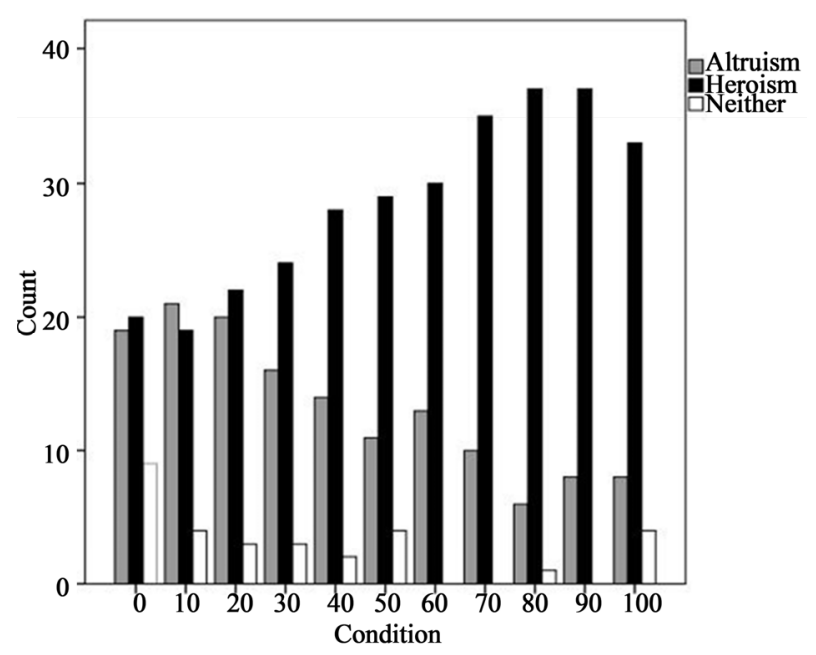

Figure 1.

Figure 1 reports the chi-square test between the eleven experimental conditions and the forced-choice measure that served as the main dependent measure in the study.

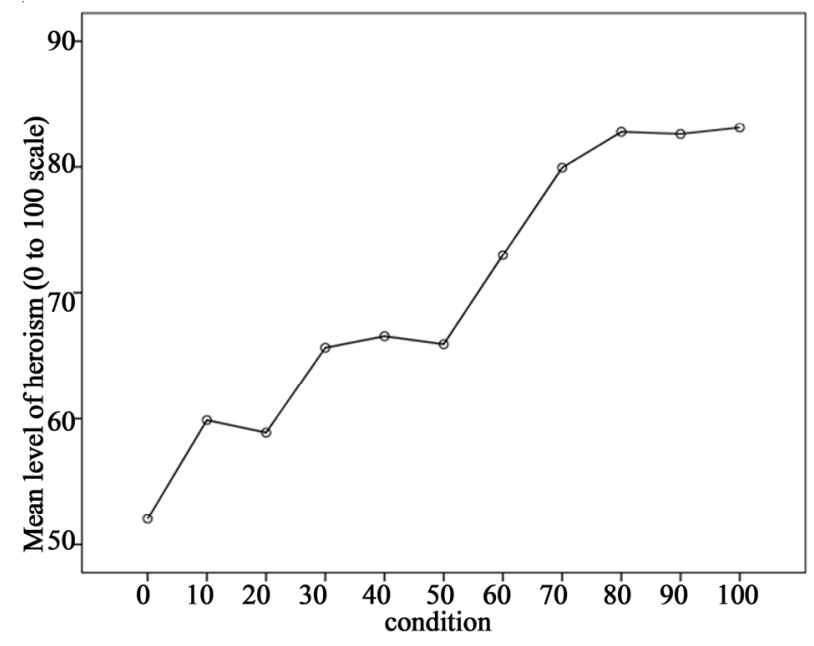

Figure 2.

A line graph is represented instead of a bar graph because the line graph allows an easier visual depiction of the increasing perceptions of heroism as risk level also increases from $0 \%$ to $100 \%$ via the experimental manipulation. The scale range for the question was 0 to 100 so it is important to note that only the top part of the scale (50 to 100) is contained in Figure 2; thus the slope of the line is actually much flatter if the entire 100-point scale range was reproduced.

measure of heroism found a sizeable relationship between the two $(r=.36, p<.001)$, thus providing additional support for the proposition that risk does produce heroism.

It is also worth noting that the correlation between the manipulation and the altruism measure revealed the same nonsignificant findings as the ANOVA analysis $(r=.03, p=.57)$. In other words, risk only impacts perceptions of heroism, not altruism. This finding is interesting because a competing rational could have argued that an act becomes even more altruistic as the danger to the actor increases. However, the present results shed light on the fact that the intuitive understanding of altruism is not dependent upon risk of harm.

\section{Heroism and Implicit Theories}

Do implicit theories influence our understanding of heroic action? The answer is yes. A logistic regression analysis testing implicit theories of personality and the manipulation (so both the situational variable and personality variable in the same model) found a significant effect, $\chi^{2}=36.75, d f=3, p<.001$, with a Cox and Snell $\mathrm{R}^{2}$ of .08 and a Nagelkerke $\mathrm{R}^{2}$ of .11 . Testing implicit theory of moral character and the manipulation produced a significant effect with an even stronger effect size, $\chi^{2}=41.56, d f=3, p<.001$, with a Cox and Snell $\mathrm{R}^{2}$ of .09 and a Nagelkerke $\mathrm{R}^{2}$ of .12.

Table 1 shows the results of testing main effects and interactions for each measure of implicit theory. The logistic regression analysis revealed significant main effects for both the manipulation and implicit theory measures. The main effect of condition is equivalent to the preceding ANOVA analysis that confirmed higher perceptions of heroism as risk increased. The main effect of implicit theory indicates that perceptions of heroism increases as the implicit theory becomes more entity orientation. In other words, as predicted, entity theorists perceive the actions are more heroic irrespective of the situational manipulation of risk levels, consistent with the theorizing behind implicit theories about entity orientation perceiving stable character, whereas incremental theorists take into account situational factors such as risk level changing in the situation.

Also as predicted, an interaction occurred between implicit theory and the situational manipulation. It is not unsurprising that the interaction occurred for the implicit theory of moral character rather than the implicit theory of personality as heroism is considered a moral action involving courage, bravery, and honesty in past research. To help understand the nature of the interaction, Figure 3 shows the interaction when measuring heroism as continuous given that logistic regression can't be visually depicted as the dependent variable is categorical, although the continuous variable was only a marginal interaction $(p=.11)$. As seen in Figure 3, incremental theorists are more influenced by the situational manipulation, as predicted. Moreover, in the absence of information about risk levels $(0 \%)$, the greatest difference occurs between entity orientation and in cremental orientation as the entity belief system is associated with making stable character inferences from a single instance

Table 1.

Logistic regression results for the categorical measure of heroism.

\begin{tabular}{cccc}
\hline \multirow{2}{*}{ Implicit theory of personality } & \multicolumn{3}{c}{ Logistic results } \\
\cline { 2 - 4 } & $\mathrm{B} / \operatorname{Exp}(\mathrm{B})$ & Wald & $p$-value \\
\hline Main effect of manipulation & $.03 / 1.03$ & 9.55 & .002 \\
Main effect of implicit theory & $.31 / 1.36$ & 4.15 & .04 \\
Interaction & $-.01 / 1.0$ & 1.83 & .18 \\
\hline \multirow{3}{*}{ Logistic Results } \\
\hline Maicit theory of moral & $\mathrm{B} / \operatorname{Exp}(\mathrm{B})$ & Wald & $p$-value \\
\cline { 2 - 4 } character & $.04 / 1.04$ & 14.58 & $<.001$ \\
Main effect of manipulation & $.54 / 1.58$ & 8.42 & $<.01$ \\
Interaction & $-.01 / 1.0$ & 4.40 & .04 \\
\hline
\end{tabular}

Note: Logistic regression involved the categorical (forced-choice) measure between altruism and heroism. Logistic regression is performed with a dichotomous measure so the option "neither" was removed for the analysis. 


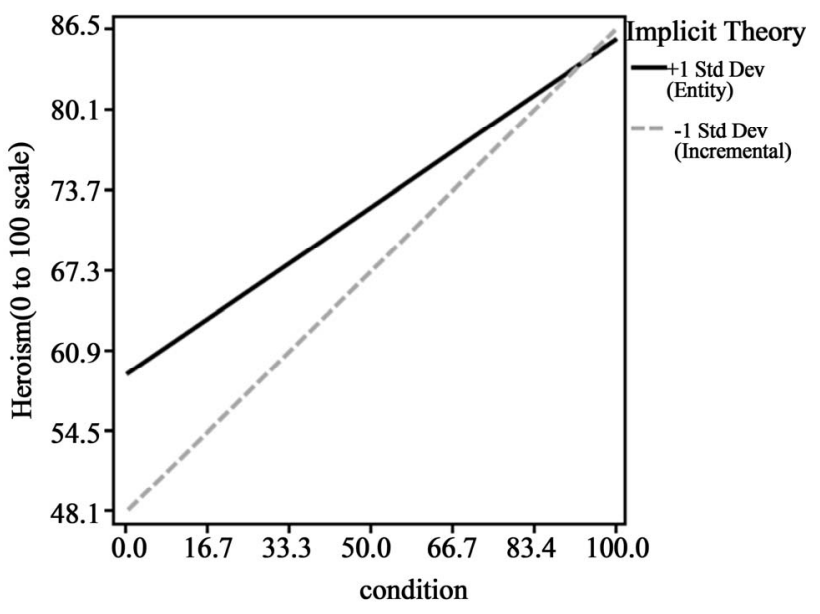

Figure 3.

The interaction between condition and implicit theory is represented using the continuous measure of heroism. The condition variable ranges from $0 \%$ to $100 \%$ risk levels.

of a person's behavior, even when that behavioral information is ambiguous.

\section{Discussion}

This study assessed the relationship between the situational constraint of risk of harm and the personality trait of implicit theories in their impact on perceptions of heroism. By investigating the situational feature across eleven levels we identified the unique nature of the relationship between risk of harm and heroism. Without substantial levels of risk, the respondents were uncertain and split about whether the act is altruistic, heroic, or neither. It is only through the manipulated information about the risk levels that the perceptions change toward a decidedly increasing level of heroism. Thus, it is the situational information itself-risk of harm-that alters the perceptions and transforms the act into distinctly heroic. A related finding is that the risk levels needed to reach a certain threshold level before the uncertainty was overcome. Apparently it requires a certain degree of risk before heroism separates from altruism. At the same time, personality traits exerted an independent effect on perceptions of heroism, and an interactive effect with the situational manipulation. The effect was partly independent in that entity theorists showed significantly higher perceptions of heroism consistent with the implicit theory literature into how entity/incremental belief systems can differentially change our perceptions of others. The personality variables also interacted with the situational manipulation through information about the particular level of risk affecting entity and incremental beliefs differently.

As a way to better understand the nature of risk in heroic action, the current research identified how the relative degree of heroism can change based upon potential harm to the actor. In doing so, the research addressed a gap in the literature and helped clarify a basic question about the escalating nature of risk in heroism. Given that a central feature of the various definitions of heroism involves risk of harm, some have argued that heroism is defined by excessive risk whereas others have argued that heroism is more than just risk-related prosocial behavior. Along those same lines, some have argued that heroism involves a broader set of behaviors that "represents a difference in kind rather than a difference in degree" (Franco, Blau, \& Zimbardo, 2011: p. 104). The present results show that there are instances where the risk of potential harm can transform what would otherwise be classified as an ambiguous prosocial act into a heroic act. In fact, the present research provides a new component for the debate on "altruism plus risk" argument given that the respondents did not switch from altruism to heroism but instead were uncertain in the absence of substantial risk levels. The escalating risk manipulation provided the basis for separating altruism from heroism in the forced-choice measure. In other words, the debate may not be about whether heroism is "altruism plus risk" when instead it may be that risk transforms broader prosocial behavior into heroism by separating it from altruism.

We also agree that heroism may involve a broader set of circumstances that are different in kind as well as degree Although in the present research the results showed that heroism had a clear linear and sizeable relationship with risk of harm, the human condition invariably affords many situational features that may separate certain kinds of heroism beyond the exclusive world of risk-related prosocial behavior. The "insufficient justification argument" by Franco, Blau \& Zimbardo (2011) certainly warrants future research, for example, in that acceptable harm or justifiable risk may change the perception of heroism. However, the very nature of this debate that some situational aspects produce different kinds of heroism falls in line with the theorizing of the current paper regarding how situational influences within the Person x Situation framework can change the perception of heroism. For example, insufficient justification for the heroic act can be conceptualized as another feature of the situation, one that further impacts how perceivers evaluate the degree of heroism, just as risk of harm is a situational feature that influenced perceptions of heroism in the current research. Just as different types of heroic acts would invariably change the exact location of the threshold level before the uncertainty was overcome, future research could investigate other situational factors like insufficient justification or any of the other criteria of the various definitions of heroism. By focusing on the core commonality among the definitions, the current research sought to address the underlying aspect of heroism.

Future research could also address other aspects of the heroic definitions, including how risk of harm influences or competes with these other definitional aspects. For example, a hero serves as an upward comparison figure and as such helps define how an individual should act. As with other upward comparison there are potential positive responses to such as a comparison (e.g., inspiration) but also possible negative responses (e.g., frustration with the self being not as good/courageous as the hero). Given the complex decision-making process of person-perception it is important to investigate emotional as well as cognitive aspects of evaluating heroes, particularly as it relates to weighing competing components. For example, connected to the issue of insufficient justification is the level of acceptable risk for a heroic act, such as how firefighters, police, and military personnel are duty-bound by their chosen profession to engage in prosocial actions to help others in need even in the presence of immediate peril. Along the same lines, would otherwise heroic actions be diminished by the presence of substantial reward for engaging in the behavior? Future research could independently manipulate the risk level compared to the reward level to determine if an optimal tipping-point determines the level of heroism under the circumstances. Many of 
the other definitional features of heroism could be grouped or classified, in fact, as those situational features that reduce the perception of heroism once the risk level has established whether or not heroism has occurred. In other words, risk level plays a pivotal role establishing whether a prosocial action rises to the level of heroism, as seen in the present research, and then other definitional features may begin to offset or reduce those perceptions with risk-related concepts such as level of reward, voluntariness of the risk, recognition of the risk, accepting the risk, and many of the other definitional features. As such, investigating the competing perceptions has value for understanding the nature of heroism and the way in which our archetypal schema of heroes is established.

\section{REFERENCES}

Becker, S. W., \& Eagly, A. H. (2004). The heroism of women and men. American Psychologist, 59, 163-178. doi:10.1037/0003-066X.59.3.163

Buhrmester, M., Kwang, T., \& Gosling, S. D. (2011). Amazon's mechanical turk: A new source of inexpensive, yet high-quality data? Perspectives on Psychological Science, 6, 3-5. doi:10.1177/1745691610393980

Chiu, C., Dweck, C. S., Tong, J. Y., \& Fu, J. H. (1997). Implicit theories and conceptions of morality. Journal of Personality and Social Psychology, 73, 923-940. doi:10.1037/0022-3514.73.5.923

Chiu, C., Hong, Y., \& Dweck, C. S. (1997). Lay dispositionism and implicit theories of personality. Journal of Personality and Social Psychology, 73, 19-30. doi:10.1037/0022-3514.73.1.19

Dweck, C. S., Chiu, C., \& Hong, Y. (1995). Implicit theories and their role in judgments and reactions: A world from two perspective. Psychological Inquiry, 6, 267-285. doi:10.1207/s15327965pli0604 1

Dweck, C. S., \& Leggett E. L. (1988). A social-cognitive approach to motivation and personality. Psychological Review, 95, 256-273. doi:10.1037/0033-295X.95.2.256

Erdley, C. A., \& Dweck, C. S. (1993). Children's implicit personality theories as predictors of their social judgments. Child Development, 64, 863-878. doi: $10.2307 / 1131223$

Franco, Z. E., Blau, K., \& Zimbardo, P. G. (2011). Heroism: A conceptual analysis and differentiation between heroic action and altruism. Review of General Psychology, 15, 99-113. doi: $10.1037 / \mathrm{a} 0022672$

Funder, D. C. (2001). Personality. Annual Review of Psychology, 52, 197-221. doi:10.1146/annurev.psych.52.1.197

Gaster, T. (1987). Heroes. In M. Eliade, \& C. J. Adams (Ed.), The encyclopedia of religion (pp. 302-305). New York: Macmillan.

Gervey, B. M., Chiu, C., Hong, Y., \& Dweck, C. S. (1999). Differential use of person information in decisions about guilt versus innocence: The role of implicit theories. Personality and Social Psychology Bulletin, 25, 17-27. doi:10.1177/0146167299025001002

Getty Images (2012). Art inside a cave depicts the hero twins of Mayan legend. URL (last checked 9 September 2012).

http://www.gettyimages.com/detail/photo/naj-tunich-cave-guatemala -high-res-stock-photography/80249083

Hero Etymology (2012). Etymology of hero. URL (last checked 9 September 2012) http://en.wikipedia.org/wiki/Hero\#Etymology

Hong, Y., Chiu, C, Dweck, C. S., Lin, D. M., \& Wan W. (1999). Implicit theories, attributions, and coping: A meaning system approach. Journal of Personality and Social Psychology, 77, 588-599. doi: 10.1037/0022-3514.77.3.588

Hong, Y., Levy, S. R., \& Chiu, C. (2001). The contribution of the lay theories approach to the study of groups. Personality and Social Psychology Review, 5, 98-106. doi:10.1207/S15327957PSPR0502 1

Jayawickreme, E., \& Di Stefano, P. (2012). How can we study heroism? Integrating persons, situations, and communities. Political Psychology, 33, 165-178. doi:10.1111/j.1467-9221.2011.00861.x

Levy, S. R., \& Dweck, C. S. (1998). Trait- versus process-focused social judgment. Social Cognition, 16, 151-172. doi:10.1521/soco.1998.16.1.151

Levy, S. R., Plaks, J. E., \& Dweck, C. S. (1999). Modes of social thought: Person theories and social understanding. In S. Chaiken \& Y. Trope (Eds.), Dual process theories in social psychology. New York: Guilford.

Levy, S. R., Plaks, J. E., Hong, Y., Chiu, C., \& Dweck, C. S. (2001). Static versus dynamic theories and the perception of groups: Different routes to different destinations. Personality and Social Psychology Review, 5, 156-168. doi:10.1207/S15327957PSPR0502_6

Levy, S. R., Stroessner, S. J., \& Dweck, C. S. (1998). Stereotype formation and endorsement: The role of implicit theories. Journal of Personality and Social Psychology, 74, 1421-1436. doi: $10.1037 / 0022-3514.74 .6 .1421$

Maloney, A. (1999). Preference ratings of images representing archetypal themes: An empirical study of the concept of archetypes. Journal of Analytical Psychology, 44, 101-116. doi:10.1111/1465-5922.00070

Mischel, W. (1990). Personality dispositions revisited and revised: A view after three decades. In L. A. Pervin (Ed.), Handbook of personality: Theory and research (pp. 111-134). New York: Guilford.

Shoda, Y (2004). Individual differences in social psychology: Understanding situations to understand people, understanding people to understand situations. In C. Sanson, C. C. Morf, \& A. T. Panter (Eds.), The sage handbook of methods in social psychology (pp. 117-141). Thousand Oaks, CA: Sage Publications.

Staats, S., Hupp, J. M., \& Hagley, A. M. (2008). Honesty and heroes: A positive psychology view of heroism and academic honesty. The Journal of Psychology, 142, 357-372. doi:10.3200/JRLP.142.4.357-372

Staats, S., Wallace, H., Anderson, T., Gresley, J., Hupp, J. M., \& Weiss, E. (2009). The hero concept: Self, family, and friends who are brave, honest, and hopeful. Psychological Reports, 104, 820-832. doi:10.2466/pr0.104.3.820-832

Tong, Y., \& Chiu, C. (2002). Lay theories and evaluation-based organization of impressions: An application of the memory search paradigm. Personality and Social Psychology Bulletin, 28, 15181527. doi: $10.1177 / 014616702237579$

White, S., \& O’Brien, J. (1999). What is a hero? An exploratory study of students' conceptions of heroes. Journal of Moral Education, 28, 81-95. doi: $10.1080 / 030572499103322$ 